\title{
Activity of FL 1060, a new $\beta$-lactam antibiotic, against urinary tract pathogens
}

\author{
D. GREENWOOD, H. LINTON BROOKS, R. GARGAN, AND F. O'GRADY
}

From the Department of Bacteriology, St Bartholomew's Hospital, London

SYNOPSIS The effect of the new $\beta$-lactam antibiotic FL 1060 on urinary tract pathogens, of which 71 were sensitive to and 100 resistant to ampicillin, is presented here. When tested by conventional ${ }^{N}$ methods FL 1060 was found to be highly active against ampicillin-sensitive strains of $E$. coli but $\omega$ phenotypically resistant variants readily emerged, particularly when a large inoculum was used. $\vec{N}$ Thirty-one per cent of ampicillin-resistant strains were found to be sensitive to less than $500 \mu \mathrm{g}_{\mathrm{O}}$ FL 1060 per $\mathrm{ml}$, and in general this antibiotic was more active than ampicillin against resistant ${ }_{\triangle}$ strains. In a system simulating the mechanical features of the urinary bladder the activity of FL 3 1060 against three sensitive strains of $E$. coli was found to be greater than ampicillin in conditions of low, but not high, osmolality.

FL 1060 (6 $\beta$-[(hexahydro-1H-azepin-1-yl)-methyleneamino]-penicillanic acid) is the most active of a group of new antibiotics-the $6 \beta$-amidinopenicillanic acids-recently described by Lund and Tybring (1972). Despite a close structural similarity to other $\beta$-lactam antibiotics, FL 1060 has different properties (Greenwood and O'Grady, 1973), notably in the nature and the spectrum of its antibacterial activity. It is much more active against Gram-negative than Gram-positive organisms (Lund and Tybring, 1972) so that an important potential therapeutic area is the treatment of urinary tract infection. This paper reports a survey of the activity in vitro of the new compound against a variety of urinary tract pathogens and an examination of its activity against infection in a model simulating conditions of bacterial growth in the urinary bladder.

\section{Materials and Methods}

FL 1060 powder was supplied by Leo Laboratories Ltd. Dilutions were made in sterile distilled water and kept at $4^{\circ} \mathrm{C}$ for not longer than four days. The bacteria studied were recent isolates from infected urines sent to the diagnostic laboratory of the hospital. Included in the survey were 71 strains sensitive to ampicillin (18 Escherichia coli, 20 Proteus mirabilis, 20 Micrococcus spp of BairdParker's subgroup 3 (Baird-Parker, 1963, 1965) and
13 Streptococcus faecalis) and 100 consecutively isolated strains resistant to ampicillin, identified, $\overline{\frac{}{D}}$ according to the scheme of Cowan and Steel (1965) as E. coli (43), Klebsiella aerogenes (13), Klebsiella $\stackrel{\square}{\triangle}$ spp (14), Enterobacter spp (4), P. mirabilis (8), $P . \stackrel{ }{\Rightarrow}$ vulgaris (1), P. morganii (1), Serratia marcescens (6), 응 Hafnia spp (5), Alcaligenes spp (1), Providence A and B (3), and Citrobacter sp (1). Sensitivity to ampicillin was judged from the zone of inhibition around $10 \mu \mathrm{g}$ discs on blood agar seeded to giveo subconfluent growth.

Minimum inhibitory concentrations (MIC) of $\stackrel{3}{3}$. FL 1060 were estimated by the agar dilution methodo using an automatic multipoint inoculator (Denley- $₹$ Tech Ltd, Billingshurst, Sussex) and sensitivity test윽 agar (Wellcotest, Wellcome Reagents Ltd, Becken- $>$ ham, Kent). The strains were maintained on nutrient agar slopes, and tubes containing $15 \mathrm{ml}$ nutrient broth were inoculated from the slopes using a straight ${ }^{\circ}$ wire and incubated at $37^{\circ} \mathrm{C}$ for six hours. Two series $N$ of antibiotic-containing plates were inoculated, one $\omega$ with undiluted culture and the other with culture diluted 1 in 1000 . The prongs of the inoculatoro deposited about $5 \times 10^{5}$ organisms from the undiluted and about $5 \times 10^{2}$ organisms from the + ? diluted culture. The MIC of FL 1060 for all the ampicillin-resistant strains and for those ampicillin-웅 sensitive strains used for morphological observation of the effect of the antibiotic were also determined by ${ }_{\circ}$ titration in broth (Casitone pancreatic digest, $\sigma$ Difco, $10 \mathrm{~g}$; yeast extract, Difco, $5 \mathrm{~g} ; \mathrm{K}_{2} \mathrm{HPO}_{4} 3 \mathrm{~g} ;$ 
$\mathrm{KH}_{2} \mathrm{PO}_{4} 1 \mathrm{~g}$; glucose $5 \mathrm{~g}$ and $\mathrm{NaCl} 5 \mathrm{~g}$ per l) containing doubling dilutions of FL 1060 from 500 to $0.015 \mu \mathrm{g}$ per $\mathrm{ml}$. One drop of a four-hour broth culture was added to each tube giving a concentration of about $10^{4}$ to $10^{5}$ organisms per $\mathrm{ml}$.

Morphological observations were made by microscopical examination of simple wet preparations.

Three strains of Escherichia coli found by tube titration to be highly susceptible to FL 1060 were examined in a mechanical system designed to simulate conditions of bacterial growth in the urinary bladder (Mackintosh, Watson, and O'Grady, 1973; O'Grady, Mackintosh, Greenwood, and Watson, 1973). In this system, $20 \mathrm{ml}$ of a fully grown broth culture, such as occurs in overnight urine or during the day in patients in whom the bladder residual volume is increased, were incubated at $37^{\circ} \mathrm{C}$ in the light path of a simple photometer which provides a continuous record of the opacity of the culture. Fresh broth was constantly added to the culture by means of a metering pump at a rate of $1 \mathrm{ml} / \mathrm{min}$ equivalent to the diurnal ureteric urine flow rate. At one-hour intervals, a pump emptied the 'bladder' (simulating micturition) leaving again the 'residual volume' of $20 \mathrm{ml}$. The influence of osmolality on the effect of the antibiotic in these conditions was studied by adding sufficient FL 1060 to produce an initial concentration of $500 \mu \mathrm{g}$ per ml and diluting the 'bladder' culture at $1 \mathrm{ml}$ per min with broth in which salt was included (osmolality: about $325 \mathrm{mOsm} / \mathrm{kg}$ ) or was omitted (osmolality: about $170 \mathrm{mOsm} / \mathrm{kg}$ ). In the latter case the overnight broth culture used to prime the system was also grown in broth without salt.

\section{Results}

\section{AMPICILLIN-SENSITIVE ORGANISMS}

The MICs of FL 1060 for 58 ampicillin-sensitive strains, read after $18 \mathrm{hr}$ at $37^{\circ} \mathrm{C}$ and using the light inoculum (about $5 \times 10^{2}$ organisms), are shown in figure 1. Most strains of $E$. coli were inhibited by $0.125 \mu \mathrm{g}$ of the antibiotic/ml although one of the 18 strains was resistant to more than $64 \mu \mathrm{g}$ FL $1060 / \mathrm{ml}$. After 48 hours' incubation, all the $E$. coli strains grew, even on the plates containing the highest concentrations of FL $1060(64 \mu \mathrm{g} / \mathrm{ml})$, if the heavy inoculum (about $5 \times 10^{5}$ organisms) had been used, but not in the plates seeded with the light inoculum (about $5 \times 10^{2}$ organisms). Five of these strains were also titrated in broth, using an inoculum of $10^{4}$ to $10^{5}$ organisms $/ \mathrm{ml}$ and incubation was continued until all the tubes showed growth. Considerable variation in behaviour was found. Some strains showed visible growth at concentrations of FL 1060 well above the MIC after 24 to 48 hours'

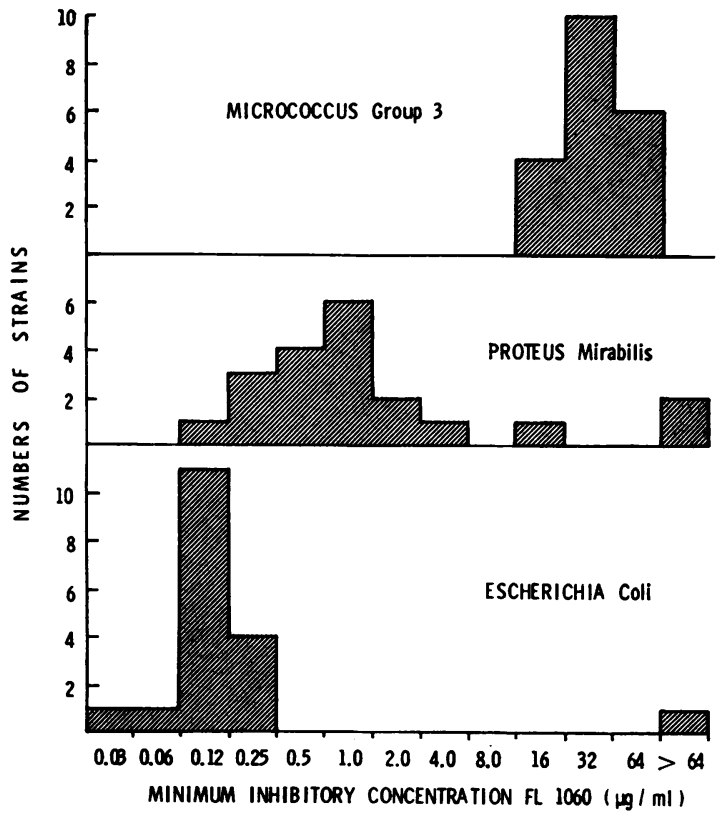

Fig 1 Distribution of MIC of FL1060 for ampicillin-sensitive strains of $\mathrm{P}$. mirabilis, E. coli, and Micrococcus subgroup 3.

incubation while others did not do so until incubated for 72 hours. Despite the appearance of active regrowth, microscopical examination showed the typical asymmetrically dividing spherical forms induced by exposure to FL 1060 (Greenwood and O'Grady, 1973) even in tubes containing low concentrations of the antibiotic.

The MICs of FL 1060 for the $P$. mirabilis strains were somewhat higher than those for $E$. coli and showed a much greater scatter (fig 1). Regrowth was studied in five of these strains using broth titrations. All yielded visible growth within $28 \mathrm{hr}$ at concentrations of FL 1060 exceeding $64 \mu \mathrm{g} / \mathrm{ml}$ although on microscopical examination the growing cells showed typical morphological damage.

Among ampicillin-sensitive Gram-positive organisms of 20 strains of Micrococcus subgroup 3 were all inhibited by 16 to $64 \mu \mathrm{g} / \mathrm{ml}$ FL 1060 , and no regrowth occurred on prolonged incubation of either plates or broth. The 13 strains of Streptococcusfaecalis were uniformly resistant to $64 \mu \mathrm{g} / \mathrm{ml}$.

\section{AMPICILLIN-RESISTANT ORGANISMS}

Some strains which grew overnight in high concentrations of FL 1060 showed marked morphological damage which was apparent even on exposure to low concentrations of the drug. The results (table I) 


\begin{tabular}{|c|c|c|c|c|}
\hline \multirow[t]{5}{*}{ Species } & \multicolumn{4}{|c|}{ Number of Strains } \\
\hline & \multirow[t]{4}{*}{ Tested } & \multicolumn{3}{|c|}{ Inhibited by FL $1060(500 \mu \mathrm{g} / \mathrm{ml})$} \\
\hline & & \multicolumn{2}{|c|}{$>500$ Resistant } & \multirow[t]{3}{*}{$<500$ Sensitive } \\
\hline & & \multicolumn{2}{|c|}{ Morphological Damage in 1 ug FL $1060 / \mathrm{ml}$} & \\
\hline & & 0 & $\rightarrow$ & \\
\hline E. coli & 43 & 22 & 2 & 19 \\
\hline K. aerngenes & 13 & 7 & 3 & 3 \\
\hline Klebsiella spp & 14 & 10 & 2 & 2 \\
\hline Enterobacter spp & 4 & 2 & 2 & 0 \\
\hline P. mirabilis & 8 & 8 & 0 & 0 \\
\hline P. vulgaris & 1 & 0 & 1 & 0 \\
\hline P. morgani & 1 & 0 & 1 & 0 \\
\hline S. marcescens & 6 & 5 & 0 & 1 \\
\hline Hafnia spp & 5 & 2 & 0 & 3 \\
\hline Alcaligenes & 1 & 1 & 0 & 0 \\
\hline Providencia spp & 3 & 1 & $\mathbf{0}$ & 2 \\
\hline Citrobacter spp & 1 & 0 & 0 & 1 \\
\hline Total & 100 & 58 & 11 & 31 \\
\hline
\end{tabular}

Table I Sensitivity of ampicillin-resistant coliform bacilli to FL 1060

ESCHERICHIA COli

$(\mu \mathrm{g} / \mathrm{ml})$

\section{FL 1060}

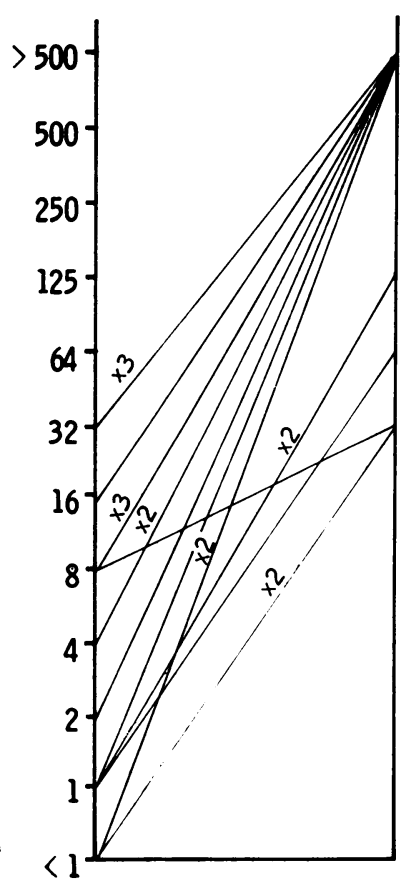

OTHER ENTIEROBACIERIA

$(\boldsymbol{m g} / \mathrm{ml})$

FL 1060

AMPICILLIN

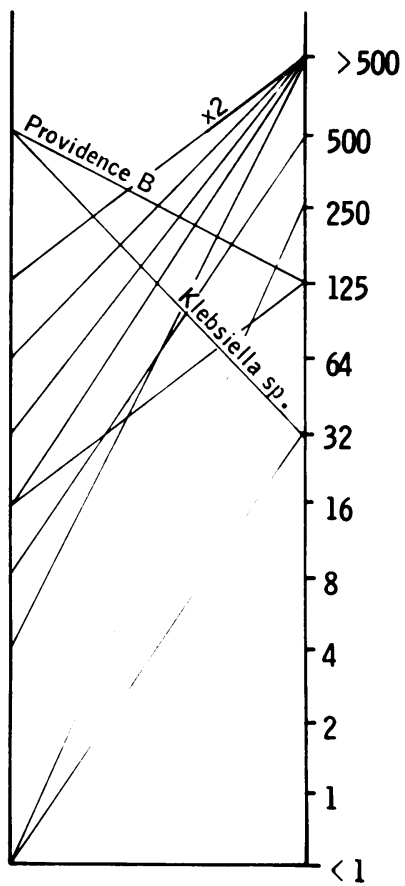

Fig 2 Cross-resistance patterns of 31 ampicillinresistant strains of $\mathrm{E}$. coli and $\dot{\mathrm{O}}$ other enterobacteria having MICs FL 1060 of $500 \mu \mathrm{g} / \mathrm{ml}$ oro less (category 3-see text). 
Number of Strains

\begin{tabular}{|c|c|c|c|}
\hline \multirow[t]{3}{*}{ Sensitive to Ampicillin $(\mu \mathrm{g} / \mathrm{ml})$} & \multicolumn{3}{|c|}{ In presence of FL $1060(500 \mu \mathrm{g} / \mathrm{ml})$} \\
\hline & \multicolumn{2}{|c|}{ Grew Overnight with Morphology } & \multirow[t]{2}{*}{ Failed to Grow } \\
\hline & Normal & Abnormal & \\
\hline $\begin{array}{l}>500 \\
128-500 \\
32-64 \\
\text { Total }\end{array}$ & $\begin{array}{r}58 \\
0 \\
0 \\
58\end{array}$ & $\begin{array}{r}4 \\
7 \\
0 \\
11\end{array}$ & $\begin{array}{r}19 \\
6 \\
6 \\
31\end{array}$ \\
\hline
\end{tabular}

Table II Comparative sensitivity of coliform bacilli to ampicillin and FL 1060

were consequently grouped into three categories: (1) 58 strains resistant to $500 \mu \mathrm{g} / \mathrm{ml}$ which showed no morphological abnormality; (2) 11 strains resistant to $500 \mu \mathrm{g} / \mathrm{ml}$ but showing conversion to spherical forms even at FL 1060 concentrations of $1 \mu \mathrm{g} / \mathrm{ml}$ or below; (3) 31 strains sensitive to 500 or less $\mu \mathrm{g} / \mathrm{ml}$.

\section{CROSS RESISTANCE}

All the strains in the first category (completely resistant to $500 \mu \mathrm{g}$ FL 1060 per $\mathrm{ml}$ ) were also resistant to $500 \mu \mathrm{g}$ ampicillin per ml. Of the 11 strains in the second category, seven were partially sensitive to ampicillin of which the MIC for these strains was 128-500 $\mu \mathrm{g}$ per $\mathrm{ml}$ (table II). The cross-resistance patterns of the 31 strains in the third category are shown in fig 2: all 19 Escherichia and four of the five Klebsiella were inhibited by less than $64 \mu \mathrm{g}$ FL 1060 per ml. Twelve of these 31 strains were partially sensitive to ampicillin and six (four $E$. coli, one Klebsiella, one Providence) were sensitive to less than $128 \mu \mathrm{g}$ ampicillin per $\mathrm{ml}$. Conversely, some sensitivity to FL 1060 was found in 19 strains

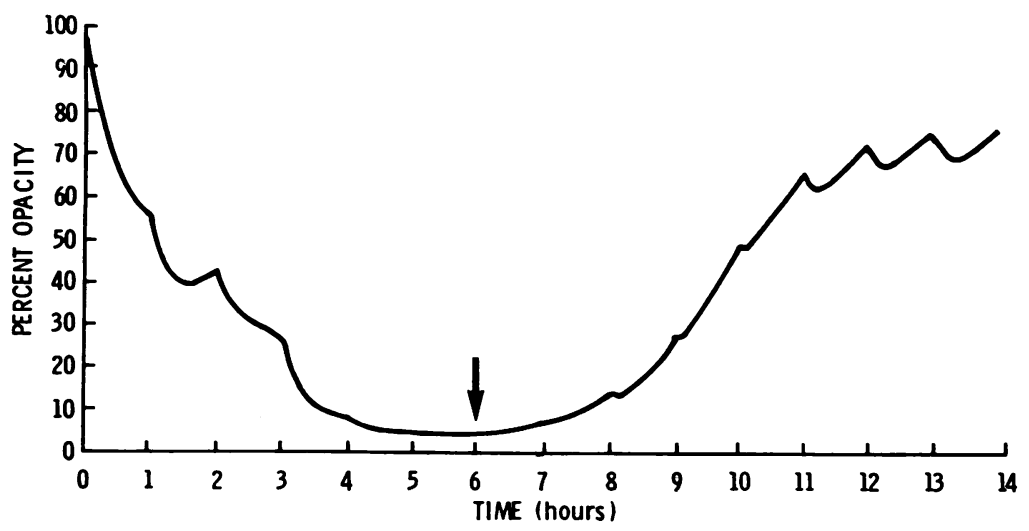

Fig 3 Typical opacitv trace of an ampicillin-sensitive E. coli strain grown in the simulated bladder system in the presence of added $\mathrm{NaCl}$. FL 1060, to achieve a concentration of $500 \mu \mathrm{g} / \mathrm{ml}$, added at time 0 . Arrow indicates point at which the concentration of FL 1060 fell below the MIC.

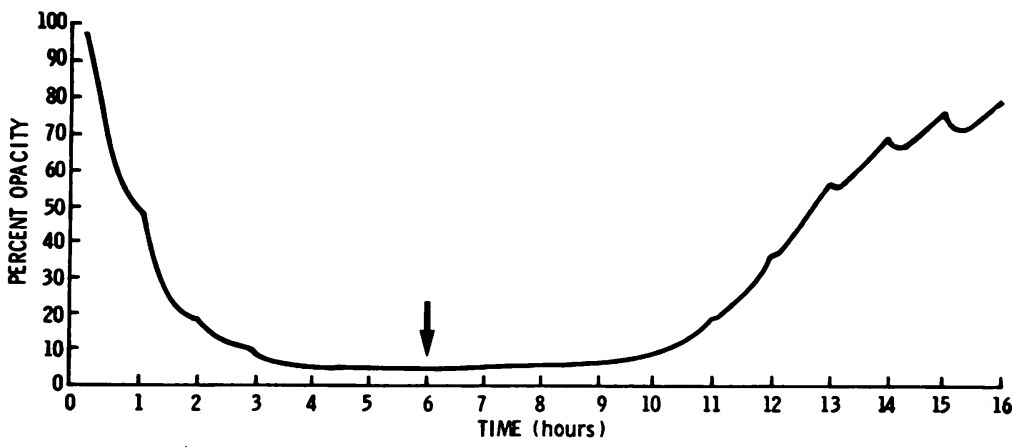

Fig 4 Typical opacity trace of an ampicillin-sensitive E. coli strain grown in the simulated bladder system in conditions of low $\mathrm{NaCl}$ concentration. FL 1060, to achieve a concentration of 500 $\mu \mathrm{g} / \mathrm{ml}$, added at time 0. Arrow indicates point at which the concentration of FL 1060 fell below the MIC. 
resistant to $500 \mu \mathrm{g}$ ampicillin per ml. Of these, 16 (13 E. coli) were sensitive to less than $64 \mu \mathrm{g}$ FL 1060 per ml. Only two strains (one Providence B, one Klebsiella) were more sensitive to ampicillin than FL 1060.

\section{SIMULATED BLADDER SYSTEM}

The presence or absence of $\mathrm{NaCl}$ in the media had no effect on the pattern of growth in the bladder model. Figures 3 and 4 show typical records of the opacity changes produced when highly sensitive strains of $E$. coli were grown in the bladder model in the presence or absence of $\mathrm{NaCl}$ with the addition of sufficient FL 1060 to produce an initial concentration of $500 \mu \mathrm{g} / \mathrm{ml}$. In the presence of $0.5 \% \mathrm{NaCl}$ (fig 3) a reduction in opacity in excess of that attributable solely to the dilution effect was first detectable about two hr after the addition of FL 1060 and regrowth commenced as the concentration of antibiotic fell below the MIC. In the absence of $\mathrm{NaCl}$ (fig 4) a sharp fall in opacity occurred earlier and regrowth took longer. The time at which regrowth was first detected varied with the strain and was as long as $15 \mathrm{hr}$ with one of the three organisms tested in the absence of $\mathrm{NaCl}$. The time which elapsed after the addition of antibiotic before regrowth was detectable is shown for each strain in table III.

\begin{tabular}{lcc}
\hline Strain & \multicolumn{2}{l}{$\begin{array}{l}\text { Time }(\mathrm{hr}) \text { before Detectoble Regrowth } \\
\text { at Osmolality }(\mathrm{mOsm} / \mathrm{kg}) \text { of }\end{array}$} \\
\cline { 2 - 3 } & 170 & 325 \\
\hline E. coli 1 & 9 & 6 \\
E. coli 2 & 11 & 9 \\
E. coli 3 & 15 & 13 \\
\hline
\end{tabular}

Table III Time after addition of antibiotic before detectable growth

\section{Discussion}

As judged by conventional titrations FL 1060 shows outstanding activity against ampicillin-sensitive strains of $E$. coli. All but one of 18 ampicillinsensitive strains were inhibited by $0.25 \mu \mathrm{g}$ or less FL 1060 per $\mathrm{ml}$-an activity at least ten times that of ampicillin in similar conditions. However, as we have previously reported (Greenwood and O'Grady, 1973) continued incubation revealed in all cases the presence of a small fraction of the population which was able to continue growth despite morphological evidence of surface damage.

Ampicillin-sensitive $\boldsymbol{P}$. mirabilis strains showed a much wider distribution of sensitivities than $E$. coli and regrowth occurred much sooner. The two factors are probably related since early regrowth masks the $\stackrel{\stackrel{0}{\overrightarrow{0}}}{\text {. }}$ true endpoint. The tendency to regrow quickly may result from the related resistance of $P$. mirabilis $\stackrel{5}{\rightarrow}$ strains to osmotic lysis (Greenwood and O'Grady, 1972) and is also in keeping with the hypothesis that phenotypically resistant cells which grow in the $\frac{\bar{c}}{\frac{5}{\sigma}}$ presence of FL 1060 have a low internal osmolality $\stackrel{\varnothing}{\varnothing}$ (Greenwood and O'Grady, 1973). Only six (4 E. coli) of the 100 ampicillin-resistant strains showed $\rightarrow$ the exceptional sensitivity to FL 1060 seen in? ampicillin-sensitive strains. Of the rest 31 showed $\vec{\omega}$ partial sensitivity to FL 1060 (MIC 1 to $500 \mu \mathrm{g} / \mathrm{ml}$ ) and many of these also showed some degree of용 sensitivity to ampicillin; nevertheless FL 1060 was nearly always the more active against these strains $i v$ (fig 2). In 19 cases $(13 E$. coli) organisms resistant to $\vec{\varphi}$ $500 \mu \mathrm{g}$ ampicillin per $\mathrm{ml}$ were inhibited by less than $N$ $64 \mu \mathrm{g}$ FL 1060 per ml after overnight incubation. 웅

In the system designed to simulate the mechanical features of the urinary bladder considerable strain 3 variation was found among highly sensitive Escherichia corresponding with the differences previously demonstrated when the same strains were exposed $\overrightarrow{0}$

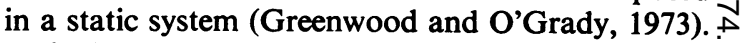
A single pulse of FL 1060 was found to suppress the growth of those sensitive strains of $E$. coli from a very high inoculum for six to 13 hours in the presence of $0.5 \% \mathrm{NaCl}$ (osmolality of medium about $325 \mathrm{mOsm} / \mathrm{kg}$ ) and nine to 15 hours in the absence of $\stackrel{\square}{\square}$ $\mathrm{NaCl}$ (osmolality of medium $170 \mathrm{mOsm} / \mathrm{kg}$ ). The $\stackrel{2}{\Rightarrow}$ osmolality of $325 \mathrm{mOsm} / \mathrm{kg}$ falls within the normal $\frac{0}{3}$ range for human urine; that of $170 \mathrm{mOsm} / \mathrm{kg}$ is easily achieved by increasing fluid intake. At the higher osmolality, such strains exposed to a $500 \mu \mathrm{g}$ per $\mathrm{ml}$ dose of ampicillin grow within about 10 hours (O'Grady et al, 1973) so that in these circumstances the performance of the two agents is similar despite the higher activity of FL 1060 in conventional 0 titration. However, the effect of osmolality on per- $₹$ formance is greater with FL 1060 than with ampicil-o lin (Greenwood and O'Grady, 1973, and unpublished $>$ observations) so that in the conditions of lower osmolality the higher activity of FL 1060 became $N$ more evident.

The therapeutic significance of phenotypic variants $\tilde{D}$ which, although remaining morphologically reactive $N$ to FL 1060, are no longer inhibited by the antibiotic (Greenwood and O'Grady, 1973) has not yet beenco established. It may be that such damaged cells will $\overparen{\varnothing}$ succumb readily to natural defence mechanisms. In $\stackrel{?}{+}$ addition, their survival in the presence of the drug $\underset{T}{T}$ probably depends on their having an internal osmolality less than that of the growth medium and $\stackrel{\square}{\square}$ it is for this reason that lowering the osmolality of $\stackrel{\mathbb{Q}}{\stackrel{Q}{Q}}$ the medium markedly enhances the effect of FL 1060. It may be, therefore, that the benefits of 
combining antibiotic therapy with diuresis in the treatment of urinary tract infection which have previously been argued on other grounds (Cattell, Sardeson, Sutcliffe, and O'Grady, 1968) will prove to be of particular importance with this agent.

We are indebted to Leo Laboratories for a grant towards the cost of this work.

\section{References}

Baird-Parker, A. C. (1963). A classification of micrococci and staphylococci based on physiological and biochemical tests. J. gen. Microbiol., 30, 409-427.

Baird-Parker, A. C. (1965). The classification of staphylococci and micrococci from world-wide sources. J. gen. Microbiol., 38, 363-387.
Cattell, W. R., Sardeson, J. M., Sutcliffe, M. B., and O'Grady F. (1968). Kinetics of urinary bacterial response to antibacterial agents. In Urinary Tract Infection, edited by F. O'Grady and W. Brumfitt, pp. 212-226. Oxford University Press, London.

Cowan, S. T., and Steel, K. J. (1965). Manuol for the Identification of Medical Bacteria. Cambridge University Press, Cambridge.

Greenwood, D., and O'Grady, F. (1972). The effect of osmolality on the response of Escherichia coli and Proteus mirabilis to penicillins. Brit. J. exp. Path., 53, 457-464.

Greenwood, D., and O'Grady, F. (1973). FL 1060-a new betalactam antibiotic with novel properties. J. clin. Path., 26, 1-6.

Lund, F., and Tybring, L. (1972). 6 $\beta$-amidinopenicillanic acidsa new group of antibiotics. Nature, [new Biol.], 236, 135-137.

Mackintosh, I. P., Watson, B. W., and O'Grady, F. (1973). Development and further applications of a simple turbidity cell for continuously monitoring bacterial growth. Phys. Med. Biol., 18, 265-271.

O'Grady, F., Mackintosh, I. P., Greenwood, D., and Watson, B. W. (1973). Treatment of 'bacterial cystitis' in fully automatic mechanical models simulating conditions of bacterial growth in the urinary bladder. Brit. J. exp. Path., 54, 283-290. 